\title{
Chapter 18 \\ Targeted Sanctions and Deterrence in the Twenty-first Century
}

\author{
Francesco Giumelli
}

\section{Contents}

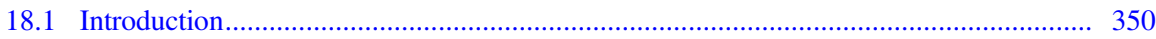

18.2 The Nexus Between Sanctions and Deterrence ....................................................... 351

18.3 The Evolution of Sanctions.................................................................................. 353

18.4 What Are Targeted Sanctions? .......................................................................... 354

18.5 Deterrence and Targeted Sanctions: Changes and Continuity ................................. 356

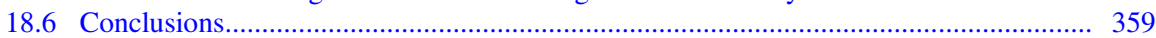

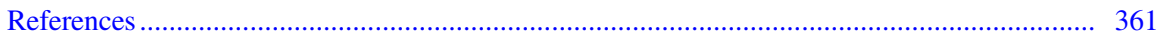

\begin{abstract}
The use of sanctions is often associated with coercion and deterrence. The former implies that sanctions contribute to changing the behaviour of targets, while the latter suggests that the damage threatened by sanctions should discourage actors from embarking on certain policies. However, sanctions have evolved substantially over the last twenty years, thus this chapter discusses whether the emergence of targeted sanctions was enough to change the classical deterrence/ sanctions relation. This chapter argues that while there are similarities with the past, there are elements of change that need to be carefully considered. On the one hand the imposition of a cost to certain policy actions, the existence of an audience and the potential impact on the wider society remain central problems for both comprehensive and targeted sanctions. On the other hand, targeted sanctions present unique features that directly interact with the concept of deterrence. First, sanctions do not target states and governments only, but also individuals and non-state actors. Second, targeted sanctions are designed to reduce their impact not only on innocent civilians, but there are clear boundaries of damage that can be inflicted on targets. Third, targeted sanctions can have a moral hazard problem, so that their imposition
\end{abstract}

\footnotetext{
F. Giumelli ( ()

University of Groningen, Groningen, The Netherlands

e-mail: f.giumelli@rug.nl 
creates an incentive for actors to embark on the very actions that sanctions aim to deter.

Keywords comprehensive sanctions - humanitarian suffering $\cdot$ targeted sanctions $\cdot$ travel restrictions $\cdot$ assets freeze $\cdot$ human rights $\cdot$ moral hazard

\subsection{Introduction}

Sanctions as an instrument of coercive diplomacy has been analysed and investigated through the lens of compellence, namely with the aim of altering the course of action of a state, or deterrence. ${ }^{1}$ In this latter case, sanctions increase the cost of certain policy actions that states would decide not to pursue because the costs would outweigh the benefits. The connection between sanctions and deterrence holds also across 'waves', since sanctions were either threatened by President Wilson in the 1920 s as a 'deadly and silent remedy' to avoid future wars or widely used during the Cold War for lower level threats than nuclear annihilation. ${ }^{2}$ The fourth wave of deterrence, however, highlighted the emergence of asymmetric threats in the international system which was posed by international terrorist groups. The emergence of this phenomenon, especially with the 09/11 attacks, has created the conditions for the evolution of sanctions from targeting states to targeting individuals and non-state groups. ${ }^{3}$ The impact of such an innovation, which is only partly represented by sanctions on terrorist groups, on how sanctions and deterrence can be interlinked when targets are not states has not been yet fully explored in the academic debate. This chapter aims to address this gap.

This chapter investigates how sanctions and deterrence interact in the twenty-first century. More specifically, the chapter explores the implications for deterrence of the emergence of targeted sanctions with a view to answer the question of the volume of the need (or the lack of it) of a broader debate to constitute the fifth wave of deterrence studies. While this final assessment is for the reader, this chapter argues that targeted sanctions share elements of continuity with their comprehensive predecessors, but they also present new and unique features that provide further nuances to the concept of deterrence. There are at least three arguments that corroborate this thesis. First, targeted sanctions aim also at individuals, and individuals behave according to different logics compared to complex organizations such as states. Second, while the classical deterrence was based on the promise of serious damage to be inflicted, targeted sanctions are designed not to inflict lethal pain on their targets. Finally, deterrence originates from the avoidance of nuclear confrontations, wide military conflicts and terrorist attacks, but sanctions

\footnotetext{
${ }^{1}$ Doxey 1971, 1972; Morgan 2012.

${ }^{2}$ Foley 1923.

${ }^{3}$ Cortright and Lopez 2002.
} 
today are used for a very long list of objectives, which fundamentally alter the premises of the instrument. This chapter has both theoretical and practical implications. The theoretical implications are clearly linked with the overall attempt done in this volume to enhance the understanding of sanctions at the onset of the twenty-first century. The practical implications are directed at both the potential enhancement that would qualify new sanctions cases and at providing useful information to base future decisions on. This analysis is supported by empirical research done on cases of sanctions imposed by the United Nations (UN) and the European Union (EU), but the cases are only demonstrative of the nature of the problem and the principles should be applicable to all cases of sanctions.

The chapter is divided into four sections. First, in Sect. 18.2, the evolution of sanctions from comprehensive to targeted will be presented. Second, in Sect. 18.3, the chapter introduces at length targeted sanctions and its potential implications for deterrence. Third, in Sect. 18.4, this discussion follows an analytical contribution which attempts to highlight continuity and change in the interaction between sanctions and deterrence. Finally, the conclusion summarizes the main argument of the chapter and indicates future lines of investigation.

\subsection{The Nexus Between Sanctions and Deterrence}

Sanctions are foreign policy instruments that are naturally linked to deterrence. For instance, Galtung in his pioneering article on Rhodesia suggests that sanctions can either punish the receiver or to make it comply with some sort of request. ${ }^{4}$ In both cases, sanctions are supposed to inflict a pain on the receiver, and the (naïve) logic goes that such economic pain would translate into political gain. The infliction of pain as punishment is understood through the deterrence prism in two ways. First, the imposition of sanctions aims to deter the repetition of certain behaviours, such as the escalation of a conflict. Second, sanctioning a receiver shapes the expectations of other actors (or potential targets in the future) of the implications of certain activities. In both cases, targets would refrain from engaging further in behaviours undesired by senders in order to avoid the negative consequences that would be caused by sanctions.

International sanctions are seen in the literature as predominantly an instrument of foreign policy. ${ }^{5}$ The first example in history is normally the Megarian decree issued by Athens as described by Thucydides in his recount of the Peloponnesian wars. The sanctions consisted of a complete trade embargo between the cities of the Delian league and the city of Megara. The same principles applied during the Medieval era when castles and cities were besieged by armies battling for

\footnotetext{
${ }^{4}$ Galtung 1967, p. 376.

${ }^{5}$ Doxey 1971; Wallensteen and Staibano 2005; Hufbauer et al. 2007.
} 
supremacy. ${ }^{6}$ Accordingly, the economic impact imposed on the population would be avoided if the rulers decided to open the gates and concede to the (sometimes various) requests of the besiegers.

The practice to limit trade for political objectives continued even when states became the main actors of the international system since the Treaty of Westphalia in 1648. Once again, sanctions would be set up with a coercive objective, namely the one to change the course of a behaviour that has already altered, ${ }^{7}$ as done by the United States on France and the Great Britain to "to induce Great Britain and France to abandon their policies of seizing neutral American ships". ${ }^{8}$ However, sanctions also started to be seen explicitly as a way to shape future expectations, and therefore behaviours, of states. During the negotiations in the aftermath of the Great War, President Wilson talked about sanctions as a "silent and deadly remedy" to avoid future wars. ${ }^{9}$ In essence, Wilson imagined that the threat of sanctions in the form of a total embargo was to be imposed on deviant states to dissuade, and thus deter, belligerent behaviours from any state. In other words, the collective security mechanism of sanctions in the League of Nations was a precursor for deterrence strategies in the nuclear era.

The advent of nuclear technology dwarfed the premises of sanctions-based deterrence, especially after the failed attempt to prevent the colonial expansion of Italy in Abyssinia in $1936 .{ }^{10}$ Sanctions played a role in the Cold War, as demonstrated by the level of attention devoted to the subject by scholarly literature, ${ }^{11}$ but they were linked to deterrence for undesirable behaviours at a lower level of threat compared to what was at stake for nuclear deterrence. In a key study on sanctions published in 1990, the list of case studies suggest that sanctions have been very frequently used to support democratic practices, to address the Apartheid, to destabilize governments among many others. ${ }^{12}$ Resorting to sanctions against specific practices is the basic logic of deterrence, so that precisely because certain practices become more 'expensive', then states would be deterred not to embark on certain behaviours. However, interestingly enough, sanctions understood as foreign policy instruments have been normally applied by states against other states (or by similar political actors before the Treaty of Westphalia, such as cities, empires and the like), but things ought to change.

\footnotetext{
${ }^{6}$ Gravett 2007.

${ }^{7}$ Giumelli 2011.

${ }^{8}$ Frankel 1982, p. 291.

${ }^{9}$ Foley 1923.

${ }^{10}$ Strang 2013.

${ }^{11}$ Galtung 1967; Doxey 1971; Baldwin 1985

${ }^{12}$ Hufbauer et al. 1990; For a sample of cases, see the website of the Peterson Institute for International Economics, available here: https://www.piie.com/summary-economic-sanctionsepisodes-1914-2006.
} 


\subsection{The Evolution of Sanctions}

In the early 1990s, sanctions looked like the measures imposed by Athens on Megara in 432 B.C. ${ }^{13}$ When Iraq decided to occupy Kuwait in 1990, the UN decided to impose a comprehensive embargo on Iraq. This sanctions regime has been accused for decades for the killing of 500,000 Iraqi children. ${ }^{14}$ While this assessment has been questioned, the fact that the comprehensive embargo on Iraq had humanitarian implications is without doubts. ${ }^{15}$ The same principles were applied to other crises in the early 1990s, such as the Federal Republic of Yugoslavia, Haiti and Rwanda. ${ }^{16}$ In these three cases, sanctions were imposed, at least, on wide economic sectors so that the humanitarian consequences became of the primary concerns of the international community.

In addition to it, sanctions were counterproductive as the real targets managed to either avoid the impact of sanctions or, occasionally, be strengthened by it. Evidence to support this thesis can be found for the four mentioned-above cases. For instance, Serbia benefited from the arms embargo as they were the only ones with weapons in the Yugoslav conflicts as well as Saddam Hussein managed to redirect the economic costs away from him and, instead, entirely on its internal opposition. In the case of Rwanda and Haiti, sanctions were not deemed to be the decisive factor in stopping the genocide or convincing the military junta to leave the country. Sanctions were not only ineffective, but they were also responsible for humanitarian consequences and, occasionally, for strengthening the targets that were supposed to be 'coerced'.

The watershed regarding the debate was the notorious assessment published by Lancet that blamed UN sanctions for the death of 500,000 children in Iran. ${ }^{17}$ This evidence triggered an academic-led debate with practitioners on the reform of sanctions in order to make them 'smart'. ${ }^{18}$ Three international processesBonn-Berlin, Interlaken and Stockholm - were organized to discuss ways in which sanctions could be designed to maximize their impact on the responsible individuals for certain policies that needed to be changed, while limiting the unnecessary humanitarian impact on innocent bystanders. ${ }^{19}$

This evolution of sanctions practice was also made possible by the emergence of the international individual responsibility principle in global politics. ${ }^{20}$ According to a state-based society, the only legitimate actors of the international system are states. This is clear when reading, for instance, the UN Charter, which allows states

\footnotetext{
${ }^{13}$ Tsebelis 1990.

${ }^{14}$ Ali and Iqbal 1999.

${ }^{15}$ Alnasrawi 2001; Hoskin 1997.

${ }^{16}$ Cortright and Lopez 1995.

${ }^{17}$ Smith et al. 1995; Ali and Iqbal 1999.

${ }^{18}$ Cortright and Lopez 2002; Brzoska 2003; Cortright et al. 2002.

${ }^{19}$ Biersteker et al. 2005.

${ }^{20}$ Sunga 1992; van Sliedregt 2012.
} 
to participate, vote and discuss in the Security Council and the General Assembly. However, the end of the Cold war saw the proliferation of international tribunals tasked with the responsibility to adjudicate individual responsibilities in domestic conflicts, such as the ones in the former Yugoslavia and Rwanda. ${ }^{21}$ The proceedings of these Tribunals/Courts took place during the discussion to set up an International Criminal Court (ICC), which became operational in 2002 thanks to the Rome Statute signed in 1998, ${ }^{22}$ which established that individuals, and not only states, could become the target of international organizations under certain conditions. This is why sanctions became 'targeted' at individuals and non-state groups beyond states.

\subsection{What Are Targeted Sanctions?}

Targeted sanctions are restriction of freedoms for individuals and non-state entities. ${ }^{23}$ While they can be directed also at certain sectors of the economy, this is not necessarily a novel factor that has been a practice also during the Cold War, such as the example of sanctions on South Africa for the Apartheid demonstrates. ${ }^{24}$ Targeted sanctions can be shaped in several ways, some of them being simply the individualization of restrictions reserved in the past to states only. Conventionally, sanctions can take the form of arms embargoes, trade restrictions, travel bans, asset freeze and financial restrictions. ${ }^{25}$

Arms embargoes are the quintessential form of sanctions used to target states and it has been used to limit access to weapons for individuals and groups such as political parties and rebel groups. Under such regimes, individuals and/or their associates as well as associates linked to certain groups cannot purchase weapons and military equipment. ${ }^{26}$ Similar restrictions have been applied to the so called 'dual-use goods', namely items that can be used with both civilian and military purposes. $^{27}$ This applies, for instance, to satellite and telecommunication technologies or to metal alloys that could be used in nuclear programs.

Weapons are a special subcategory of trade sanctions and targeted sanctions also limit access to non-military items for individuals and groups. The ratio for such a measure is to either undermine the economic position or to constrain the capacity to operate for individuals and groups. For instance, the economic position of individuals and groups is affected by the ban on luxury items imposed on the

\footnotetext{
${ }^{21}$ Schabas 2006.

${ }^{22}$ Lee 1999.

${ }^{23}$ Cortright et al. 2002; Cortright and Lopez 2002.

${ }^{24}$ Crawford and Klotz 1999.

${ }^{25}$ Biersteker et al. 2016.

${ }^{26}$ Brzoska and Lopez 2009.

${ }^{27}$ Tamada and Achilleas 2017.
} 
Democratic People's Republic of Korea (DPRK) and the ban on certain activities that were directly linked to the economic position of the Revolutionary Guard in Iran. Once again, these sanctions are to be added to the list of potentially very invasive sanctions, such as EU sanctions on the Iranian export of oil or the UN ban on diamonds from Liberia and Sierra Leone.

Other measures gained the lion's share of individual sanctions, namely travel bans and freeze of assets. By definition, the ban from traveling and the freezing of assets are measures that directly affect individual freedoms. These restrictions can be either based on a function that is being performed, such as restrictions insofar as an individual is serving in Government, or because of actions, such as the violation of human rights. These types of sanctions have been imposed several times since the UN inaugurated the era of targeted sanctions with Al Qaeda/Taliban in 1999 and, especially, after the attacks on 09/11 when hundreds of names were added to the list of the 1267 Committee and were subjected to a travel ban and a freeze of assets. ${ }^{28}$ Often a freeze of assets is also intended as a financial restriction because payments from and to individuals subjected to freeze of assets are also forbidden. However, financial restrictions regard more than payments, but can also regard the purchase of bonds and the provision of insurance services, such as in the case of Russia and Iran.

Quite unexpectedly, practitioners were caught by surprise when domestic and international courts started to review cases of allegedly human rights violations in cases of individual listings. The Kadi case, which was an historical decision that brought the Court of Justice of the European Union on the verge of reviewing the decisions of the Security Council, ${ }^{29}$ was a wake-up call to all as targeted sanctions posed severe legal challenges to this emerging practice of sanctions. For instance, while a state's access to international markets could be restricted as per Chapter VII of the UN Charter, individuals' restriction of freedom is subjected to different standards and requirements so that basic principles of due process and effective remedy should apply. ${ }^{30}$ Additionally, humanitarian exemptions and exceptions needed to be considered as while the responsibility chain for states subjected to sanctions can be up for discussion, the responsibility for an individual in need of medical care that has no access to his personal funds to cover for his/her treatment due to sanctions is clearly falling on the shoulders of the senders of sanctions. ${ }^{31}$

Overall, targeted sanctions present overlaps with former sanctions practices when the only possible and direct targets were states. However, legal challenges as well as impact perception from targeting individuals clearly sets a difference between the 'classic' way of understanding sanctions and the more recent 'targeted' form. In other words, if changes are affecting the functioning of sanctions in

\footnotetext{
${ }^{28}$ Biersteker et al. 2016.

${ }^{29}$ Eckes 2008.

${ }^{30}$ Biersteker and Eckert 2006.

${ }^{31}$ Graf Sponeck 2002.
} 
general, this chapter explores whether a difference could emerge also by exploring the deterrence/sanctions nexus. The next section addresses this question.

\subsection{Deterrence and Targeted Sanctions: Changes and Continuity}

The evolution of sanctions from comprehensive to targeted poses challenges to the conventional understanding of the sanctions/deterrence nexus. Certainly, there are elements of continuity in how sanctions relate to deterrence, but there are at least three fundamental changes. First, targets are also individuals and their costs/benefits calculations differ from the ones of states upon which the conventional deterrence theory is also based. Second, while deterrence works (or can work) because certain actors could face a heavy sanction (i.e. nuclear annihilation), targeted sanctions are designed to cause limited damages. Finally, targeted sanctions have a moral hazard problem. The three premises, which will be elaborated below, give way to three theoretical considerations that will follow.

Certainly, targeted sanctions are aiming at individuals and entities, but they are still sanctions that are used in case of undesirable behaviours. This means that there are inevitable similarities with how sanctions contribute to deterrence. First and foremost, sanctions intend to add a cost to certain actions. Whether states or individuals, the ultimate objective of sanctions is to alter the cost/benefit calculations of targets so they would be deterred to embark on certain policies. This occurs regularly for practices that are, more or less, becoming consistent across time and space. For instance, the US, the EU and the UN all target human rights violations with the imposition of sanctions, the cases of Iran, Belarus and Venezuela are only a few in a long list of crises that were subjected to human rights sanctions in the last years. This applies also to conflicts. For instance, the government of South Sudan expressed concerns in several occasions for the threat to be the target of an arms embargo imposed by the United Nations, therefore the decisions of President Kiir were naturally influenced by this possibility.

Second, the very act of imposing sanctions should not only deter the direct targets, but it should also prevent future repetition of similar behaviours by other targets. In other words, sanctions events between targets and senders are observed by an audience of potential targets in the future. This applies to the various crises under which sanctions have been used, whether it is about human rights violations or non-proliferation policies. For instance, any state interested in developing a nuclear program would not be indifferent to the experiences of Iran and North Korea. Similarly, actors assess the opportunity to trigger or cause a conflict also by factoring in the possibility to receive sanctions, therefore conflicts might be prevented precisely to avoid the negative consequences of sanctions.

Finally, also targeted sanctions can have a rather broad impact on societies to similar extent than comprehensive ones. Indeed, if targeted sanctions are applied 
either on multiple economic sectors, such as the case of North Korea, or on crucial ones, such as the case of oil for Iran, it is inevitable that the impact of sanctions can be felt across the targeted society. This phenomenon is only amplified by the fact that targeted sanctions are mainly implemented by firms and companies through de-risking decisions. ${ }^{32}$ For instance, sanctions on Syria do not cover most trade, but the complexity of the situation on the grounds does not allow companies to engage in export/import activities without serious risks and, therefore, they 'de-risk' and decide to abandon any commercial operation with the country. ${ }^{33}$

These similarities notwithstanding, there are at least three aspects of targeted sanctions that challenge the classical deterrence/sanctions nexus. First, targeting states is not the same thing than targeting individuals or entities. In statistics, generating inferences on individuals from groups is a formal mistake known as ecological fallacy. In political science, complex organizations are often the combination of individual's preferences, therefore the way in which a complex organization (or an institution) behaves can be radically different from the individual preference of each of its members. For instance, individuals have a time span that can differ from the one of institutions. Any citizen of a country would behave thinking that their state will last longer than each of them. Additionally, the wellbeing of individuals is not always linked with the wellbeing of a nation. This means that individuals would not respond to economic pain in the same way that deterrence theory expects states to do. In occasions as identified also above, sanctions worked in favour of the very individuals that were supposed to be targeted, while affecting severely the wider society as in the case of Iraq in the 1990s.

Second, while the essence of comprehensive sanctions was to inflict a damage to targets so others would not behave alike, targeted sanctions are designed to reduce their impact to the minimum. This is not to say that sanctions are, therefore, toothless, but this certainly sets a difference with the classical approach to deterrence. Firstly, states do not have human rights, while individuals do. This means that targeted sanctions are structurally limited in their impact on individuals. For instance, the listing of individuals has been compared to criminal proceedings, therefore evidence need to be presented, 'indicted' individuals need to be heard, and there should be procedures to rectify mistakes made by listing authorities. In other words, individuals have rights that cannot be easily waived, which limit the impact of deterrence as understood "in a classical" sense. Rather, principles from criminal deterrence could apply as elaborated below.

Additionally, targeted sanctions are designed to limit humanitarian consequences on direct and indirect targets. The rather narrow design is the acceptance of a reduced 'impact' of sanctions in general, but the combination with human rights concerns means that the impact cannot hamper the minimal wellbeing of targets. For instance, payments for medical expenses and basic needs are to be authorized by the competent authorities. This is also true for the negative consequences of the

\footnotetext{
${ }^{32}$ Bures 2015; Bures and Carrapico 2018.

${ }^{33}$ Daher and Moret 2020.
} 
wider population as a number of exemptions and exceptions are normally included in a sanctions regime. These refer, for instance, to the provision of humanitarian aid and the purchase of equipment for international missions. Further details on this point would go beyond the scope of this chapter, but it should suffice to state that deterrence doctrine would be concerned partly with the wider impact, but less with the consequences for individuals directly targeted. This holds true also for the fourth wave of deterrence literature.

Finally, targeted sanctions can increase the likelihood of the behaviours that they intend to discourage as they present a problem of moral hazard. Comprehensive sanctions were criticized because they would trigger the rally around the flag effect. Accordingly, the population under sanctions tends to side with its own government in order to withhold the pressure from an outsider force, as it happened in the case of Southern Rhodesia already in the $1960 \mathrm{~s}^{34}$ Targeted sanctions were to avoid this unintended effect as the negative impact would not fall on the shoulders of the population, but if targeted sanctions are imposed (or can be imposed) in a conflictual situation, one party in conflict might have the incentive to provoke a conflict if it expects that targeted sanctions would be imposed on the other side. This argument was made to explain the breaking out of the Kosovo war. Since the international community had already expressed its preference against Serbia and Milosevic, parties in Kosovo engaged in provocative actions that, eventually, led to the conflict with the international intervention. ${ }^{35}$ Targeted sanctions can have the same impact and, as such, they can have the opposite effect of what claimed by a potentially generalizable deterrence strategy.

These points lead to two broad considerations regarding the deterrence/sanctions nexus for a potential fifth wave in deterrence literature. First, deterrence at the international level is approximating the functioning of criminal deterrence in the domestic level. ${ }^{36}$ The fourth debate focused on the asymmetric threat posed by international terrorism, so non-state actors acquired the status of international actors and, in a way, were treated as such. Therefore, they would suffer the consequences of their actions with the use of lethal violence against them, as demonstrated by the military response to the attacks on 09/11. At the same time, international terrorism would be worth global attention precisely because they would attempt the highest of the values, namely the security of states and their citizens. Instead, targeted sanctions have been used with an ever-growing list of crises, from international terrorism, to non-proliferation, conflict management, post-conflict reconstruction, but also asset recovery (the EU) and for combating organized crime and human trafficking (the US).

Second, the over-utilization of sanctions and their apparent light impact could undermine, rather than strengthen, an international criminal deterrence doctrine. For instance, nuclear deterrence was built on the fact that fact that nuclear weapons

\footnotetext{
${ }^{34}$ Galtung 1967.

${ }^{35}$ Kuperman 2008.

${ }^{36}$ Chalfin and McCrary 2017.
} 
were used only once. The potentially destructive power of nuclear weapons was enough to make deterrence a viable approach to pursue. Instead, targeted sanctions have been growingly used and this could contribute to reduce their role in substantiating a deterrence strategy, or at least to consider deterrence a low-intensity doctrine. First, the practice of targeted sanctions show that they can be easily circumvented. There are numerous cases also in the European Union, where the capacity is certainly high, of companies being caught for violation of sanctions regimes. ${ }^{37}$ Second, the evolution of sanctions at the micro-level has favoured the creation of countermeasures to further limit their impact. For instance, sanctions on Swift in 2012 have sparked a debate towards the creation of alternative platforms for international payments. ${ }^{38}$ Second, the consolidation of crypto currencies has also provided further instruments to circumvent the impact of targeted sanctions. In general, the success of deterrence is fundamentally based on the consequences that actors will pay in case of certain behaviours. However, this sanctions inflation may have contributed to the establishment of a very different sanctions/deterrence nexus that would be easier understood as an instrument of criminal domestic politics rather than security/international politics.

\subsection{Conclusions}

The use of sanctions is often associated to coercion and deterrence. The former implies that sanctions contribute to change the behaviour of targets, while the latter suggests that the damage threatened by sanctions should discourage actors from embarking on certain policies. However, sanctions have evolved substantially in the last twenty years, thus this chapter discussed whether the emergence of targeted sanctions was enough to change the classical "deterrence/sanctions nexus". This chapter argued that while there are similarities with the past, there are elements of change that need to be carefully considered.

On the one hand, a sanction is a sanction, therefore the imposition of a cost to certain policy actions, the existence of an audience and the potential impact on the wider society remain central problems for both comprehensive and targeted sanctions. On the other hand, targeted sanctions present unique features that directly interact with the concept of deterrence. First, sanctions do not target states and governments only, but also individuals and non-state actors. Second, targeted sanctions are designed to reduce their impact not only on innocent civilians, but there are clear boundaries of damage that can be inflicted on targets. Third, targeted sanctions can have a moral hazard problem, so that their imposition creates an incentive for actors to embark on the very actions that sanctions aim to deter.

\footnotetext{
${ }^{37}$ Giumelli and Levi 2016.

${ }^{38}$ Majd 2018.
} 
These features indicate that targeted sanctions are used in a global system targeting a wide range of behaviours and several actors involved at any levels of illicit activities. This system of deterrence is an evolution from the fourth wave as it does not only attempt to address a security related matter (i.e. terrorism), but it extends to a series of lower risk crises that would be better understood through a governance prism rather than a foreign policy one. As such, principles underlying criminal deterrence should be used to complement classical deterrence literature.

There are theoretical and practical implications from this viewpoint. From a theoretical angle, adding the individual level to the deterrence literature indicates the formation, or the understanding, of a different international system. As such, this study and approach should draw from the very wide debate that tries to understand the nature of the international system and international politics. While one of the main assumptions is to look at the world as divided in states, this analysis suggests that a multilevel governance approach might be more appropriate to make sense of the contemporary complexities of global politics. Second, the study of sanctions practices as well the analysis of the ways in which sanctions are evaded is a way to study different configuration of power structures and its uses in the international system. This directly contributes to understanding deterrence beyond material considerations strongly linked to costs and impacts of sanctions. Instead, sanctions and deterrence have (or should have) a common normative background that indicates what are the behaviours that should not be repeated. Indeed, the shift from foreign policy to governance in understanding sanctions presupposes that decision-making will be overtime less 'political' and more 'rule based'. The study of the rules upon which international criminal deterrence works is a worthwhile venue for future research.

At the same time, targeted sanctions can contribute to criminal deterrence, but also to deterrence in general, if they manage to have an impact on targets. Therefore, given targeted sanctions work at a micro level, the issue of institutional capacity is certainly to be taken more seriously than what has been done so far. First, the quality of listing targets is of essence, therefore deep knowledge of targets and targeted societies is crucial. A policy implication from this starting point is that public authorities making listing decisions ought to improve their knowledge base and their capacity to acquire new information when needed. Consequently, this becomes an issue of coordination with non-state actors that could have crucial information not in the hands of public authorities. This is already happening, for instance, with the regulation of the financial sector and the forced cooperation that banks and the like must guarantee to governments. Second, there is an issue of capacity building in the private sector. Since for-profit actors are becoming central allies in gathering information, it is of utmost importance that they are provided with the necessary information and expertise to fully comply with the spirit of the regulation. At the moment, the level of preparedness across countries and legal system is very uneven, which undermines the capacity for sanctions to credibly contribute to (criminal) deterrence. Finally, criminal sanctions reproduce a cat and mouse process, so targets and potentially targeted societies make preparations to be resilient in case of being targets of sanctions. While this is not new to deterrence 
experts, the individual level of criminal deterrence requires a more attentive and capillary cooperation across different national and global institutions that is often undermined by political and strategic considerations. Although this cooperation is difficult, it is a necessary (yet insufficient) step to ensure that there could be a meaningful discussion regarding (criminal) deterrence in the twenty-first century.

\section{References}

Ali M M, Iqbal S H (1999) Sanctions and Childhood Mortality in Iraq. Lancet 27.355:1851-1857 Alnasrawi A (2001) Iraq: Economic Sanctions and Consequences, 1990-2000. Third World Quarterly 22.2:205-18

Baldwin D A (1985) Economic Statecraft. Princeton University Press, Princeton NJ

Biersteker T J, Eckert S (2006) Strengthening Targeted Sanctions Through Fair and Clear Procedures. Watson Institute for International Studies, Providence RI

Biersteker T J, Eckert S E, Halegua A, Romaniuk P (2005) Consensus from the Bottom Up? Assessing the Influence of the Sanctions Reform Process. In: Wallensteen P, Staibano C (eds) International Sanctions: Between War and Words in the International System. Routledge, London

Biersteker T J, Eckert S E, Tourinho M (2016) Understanding United Nations Targeted Sanctions. Cambridge University Press, Cambridge

Brzoska M (2003) From Dumb to Smart? Recent Reforms of UN Sanctions. Global Governance 9.4:519-35

Brzoska M, Lopez G A (2009) Putting Teeth in the Tiger: Improving the Effectiveness of Arms Embargoes. Emerald Group Publishing, Bingley UK

Bures O (2015) Political Corporate Social Responsibility: Including High Politics? Journal of Business Ethics 129:689-703

Bures O, Carrapico H (2018) Security Privatization. How Non-Security-Related Private Businesses Shape Security Governance. Springer, Cham Switzerland

Chalfin A, McCrary J (2017) Criminal Deterrence: A Review of the Literature. Journal of Economic Literature 55.1:5-48

Cortright D, Lopez G A (1995) Economic Sanctions: Panacea or Peacebuilding in a Post-Cold War World? Westview Press, Boulder CO

Cortright D, Lopez G A (2002) Smart Sanctions: Targeting Economic Statecraft. Rowman \& Littlefield Publishers, Lanham MD

Cortright D, Lopez G A, Rogers E S (2002) Targeted Financial Sanctions: Smart Sanctions That Do Work. In: Cortright D, Lopez G A (eds) Smart Sanctions: Targeting Economic Statecraft. Rowman \& Littlefield Publishers, Lanham MD, 23-40

Crawford N, Klotz A (1999) How Sanctions Work: Lessons from South Africa. St. Martin's Press, New York

Daher J, Moret E S (2020) Invisible Sanctions: How Over-Compliance Limits Humanitarian Work on Syria. Challenges of Fund Transfer for Non-Profit Organizations Working on Syria https:// impact-csrd.org/reports/Invisible_Sanctions_IMPACT_EN.pdf Accessed: 14 May 2020

Doxey M P (1971) Economic Sanctions and International Enforcement. Oxford University Press, Oxford

Doxey M (1972) International Sanctions: A Framework for Analysis with Special Reference to the UN and Southern Africa. International Organization 26.3:527-50

Eckes C (2008) Judicial Review of European Anti-Terrorism Measures-The Yusuf and Kadi Judgments of the Court of First Instance. European Law Journal 14.1:74-92

Foley H (1923) Woodrow Wilson's Case for the League of Nations (edited). Princeton University Press/Oxford University Press, Princeton/London 
Frankel J A (1982) The 1807-1809 Embargo Against Great Britain. Journal of Economic History 42.2:291-308

Galtung J (1967) On the Effects of International Economic Sanctions: With Examples from the Case of Rhodesia. World Politics 19.3:378-416

Giumelli F (2011) Coercing, Constraining and Signalling. Explaining UN and EU Sanctions after the Cold War. ECPR Press, Colchester

Giumelli F, Levi G (2016) Sanzioni: Alle Imprese Europee La Multa Arriva Dagli Usa. http:// www.lavoce.info/archives/41389/sanzioni-alle-imprese-europee-la-multa-arriva-dagli-usa/ Accessed: 12 May 2020

Graf Sponeck H C (2002) Sanctions and Humanitarian Exemptions: A Practitioner's Commentary. European Journal of International Law 13.1:81-87

Gravett C (2007) The History of Castles, Fortifications around the World (revised and updated edn.). Rowman \& Littlefield Publishing, Lanham MD

Hoskin E (1997) The Humanitarian Impacts of Economic Sanctions and War on Iraq. In: Weiss T G (ed) Political Gain and Civilian Pain: Humanitarian Impacts of Economic Sanctions. Rowman \& Littlefield Publishers, Lanham MD/Oxford, 91-148

Hufbauer G C, Schott J J, Elliott K A (1990) Economic Sanctions Reconsidered. 2nd edn. Institute for International Economics, Washington DC

Hufbauer G C, Schott J J, Elliott K A, Oegg B (2007) Economic Sanctions Reconsidered. Peterson Institute for International Economics, Washington DC

Kuperman A J (2008) The Moral Hazard of Humanitarian Intervention: Lessons from the Balkans. International Studies Quarterly 521:49-80

Lee R S K (1999) The International Criminal Court: The Making of the Rome Statute: Issues, Negotiations, Results. Kluwer Law International, The Hague/London

Majd M (2018) The Cost of a SWIFT Kick: Estimating the Cost of Financial Sanctions on Iran. In: Epstein G A (ed) The Political Economy of International Finance in an Age of Inequality. Soft Currencies, Hard Landings. Edward Elgar Publishing, Cheltenham UK/Northampton MA, pp 175-193

Morgan P M (2012) The State of Deterrence in International Politics Today. Contemporary Security Policy 33.1:85-107

Schabas W (2006) The UN International Criminal Tribunals: The Former Yugoslavia, Rwanda and Sierra Leone. CUP, Cambridge

Smith F, Mary C, Zaidi S (1995) Health of Baghdad's Children. Lancet 346

Strang B G (2013) Collision of Empires: Italy's Invasion of Ethiopia and Its International Impact. Routledge, Abingdon/New York, NY

Sunga L S (1992) Individual Responsibility in International Law for Serious Human Rights Violations. Martinus Nijhoff, Dordrecht

Tamada D, Achilleas P (2017) Theory and Practice of Export Control. Balancing International Security and International Economic Relations. Springer, New York

Tsebelis G (1990) Are Sanctions Effective? A Game-Theoretic Analysis. Journal of Conflict Resolution 34.1:3-28

Van Sliedregt E (2012) Individual Criminal Responsibility in International Law. Oxford University Press, Oxford UK

Wallensteen P, Staibano C (2005) International Sanctions: Between Words and Wars in the Global System. Frank Cass, London/New York 
Francesco Giumelli is Associate Professor in, and Deputy Head of the Department of International Relations and International Organization at the University of Groningen. A former Jean Monnet Fellow at the European University Institute (EUI), Fiesole, Italy, he has published widely on EU and UN sanctions.

Open Access This chapter is licensed under the terms of the Creative Commons Attribution 4.0 International License (http://creativecommons.org/licenses/by/4.0/), which permits use, sharing, adaptation, distribution and reproduction in any medium or format, as long as you give appropriate credit to the original author(s) and the source, provide a link to the Creative Commons license and indicate if changes were made.

The images or other third party material in this chapter are included in the chapter's Creative Commons license, unless indicated otherwise in a credit line to the material. If material is not included in the chapter's Creative Commons license and your intended use is not permitted by statutory regulation or exceeds the permitted use, you will need to obtain permission directly from the copyright holder.

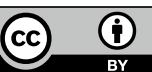

